\title{
Gender and cultural diversity in sport organisations
}

\author{
TRACY TAYLOR \\ University of Technology, Sydney
}

\section{Abstract}

A diversity audit is used to profile gender and cultural diversity in selected Australian community sport clubs. The assessment aims to create a better understanding of sport and cultural diversity and provide the data to facilitate awareness of these issues in sport. The present study focussed on five team sports and their associated community clubs. Fifty clubs were surveyed about their policies, practices and attitudes to gender and cultural diversity. To complement this information interviews were undertaken with ten club officials and thirty-seven players to gain their perspective on the issues at hand. The data revealed that most clubs were aware of gender considerations and were actively trying to increase female participation across all dimensions of club activity from players to broad members. However, very few clubs had explicitly addressed aspects of cultural diversity and increasing diversity was not given a high priority. In a country with a high level of cultural diversity such attitudes and approaches seem incongruous with progress. Inclusion of cultural and gender diversity offers sporting organisations a broader mixture of players, volunteers and employees and increased stakeholder benefits.

Keywords: cultural diversity, multiculturism, gender, sport organisation

$$
\text { * * * }
$$

\section{Introduction}

It is anticipated that the cultural diversity of western countries, including Australia, will increase in the coming decades (Department of Immigration and Multicultural Affairs, 1999). Cultural diversity will have a significant impact on sport and recreation organisations in their future recruitment and retention of participants, volunteers, spectators and employees (Doherty \& Chelladurai, 1999). This research investigates how gender and cultural diversity management is approached by community sport organisations. The empirical research component was undertaken in Australia, a country with a substantive level of cultural diversity. The research highlights both the problems and opportunities associated with diversity management. Successful management of gender and cultural diversity is critical for a plethora of considerations ranging from dimensions of social responsibility and justice to the more pragmatic considerations of maintaining or gaining competitive advantage.

\section{Cultural diversity}

Issues surrounding cultural diversity are central to the future of Australia and many other settler nations that have sustained immigration intakes. In the 1996 census the Australian population was comprised of over 23 percent overseas-born people from 224 different countries (Australian Bureau of Statistics, 2000). Government projections suggest that the cultural diversity of Australia will continue to increase over the next ten years (Department of Immigration and Multicultural Affairs, 
1999). This growing diversity will have a significant impact on the human resource dimensions of all sport organisations.

Cultural diversity is reflective of a distinct set of vales, attitudes, practices and language that are shared amongst group members (Cox, 1994). Organisational studies research has reported positive outcomes associated with the effective management of cultural diversity (Palich \& Gomez-Mejia, 1999). In an extensive review of previous research on workplace practices Milliken and Martins (1996) concluded that cultural diversity in the workplace provided benefits associated with an increased pool of human resource capital and generation of alternative approaches. Similar conclusions have been reached in several other studies of cultural diversity in organisations (Duchatelet, 1998; Gomez-Mejia \& Palich, 1997; Mohapatra, 1996; Ng \& Tung, 1998; Strydom \& Erwee, 1998). However, cultural diversity can also be a source of conflict if it is not managed effectively (Mendoza, 1999) and can disadvantage women (Kalanzis, 1992). There are many ethical dilemmas associated with managing diversity associated with the politics of difference, the difficulties of negotiating conflicting discourses and in the inherent dangers of imposing colonising values on ethnic minority groups (Elmes \& Connelley, 1997).

The need to successfully manage diversity is particularly relevant in societies, such as Australia, due to their high proportion of migrant populations (Stone, 1998). Previous research has shown that failure to deal with the attendant issues can lead to the creation of negative ethnic stereotypes that severely limit the participation opportunities of individuals from particular race, ethnic and religious backgrounds (Fleming, 1994; Jarvie, 1991; Long et al., 1997; Taylor, 2000; Toohey \& Taylor, 1999). Several researchers in sport studies have already suggested that Australian sports organisations will need to respond to issues of cultural diversity if they are to survive in an increasingly competitive sports environment (Booth \& Tatz, 2000; Cashman, 1995; Mosely, 1994; Mosely et al. 1997; Rowe, 1996; Stoddart, 1994). Research to date has also indicated that sports have not fully capitalised on this market. Stud- ies have revealed that overseas-born individuals are significantly less represented as participants in sporting activities (Australian Bureau of Statistics, 1998), have lower levels of physical activity (Armstrong, Bauman \& Davies, 2000), are under-represented as sports spectators (Australian Bureau of Statistics, 1998) and are less likely to hold volunteer roles or paid positions in sports organisations (Fitzpatrick \& Brimage, 1998).

\section{Women and cultural diversity}

It has been long êstablished that women in general have faced exclusionary obstacles to their sport participation (Clarke, Humberstone \& Hargreaves, 1997; Hall, 1996; Hargreaves, 1993; Henderson \& Bialeschki, 1994; Theberge \& Birrell, 1994a, 1994b). Women from minority cultural groups are a sub-population that has been identified as the 'other' in previous research (hooks, 1989; Prakash, 1994). Sport theorists that have researched 'otherness' suggest that individuals and groups from outside the mainstream have been historically marginalised in sports practices (Bhandari, 1991; Hargreaves, 1994; Henderson \& Ainsworth, 2000; Long et al, 1997).

In Australia, the under-representation of this sub-group of women has been quantitatively documented across all dimensions of sport involvement. Previous studies have indicated that women from minority cultural groups are significantly less likely to participate in sports activities (Australian Bureau of Statistics, 1998), engage in physical activity (Armstrong, Bauman \& Davies 2000), or become sports spectators (Australian Bureau of Statistics, 1998). They are also less likely to hold either volunteer roles or paid positions in sports organisations (Fitzpatrick and Brimage, 1998). An Australian Sports Commission study of sport and women from non-English-speaking backgrounds found that fewer than 10 per cent of sport providers surveyed had programs or policies addressing the needs of women from a non-English-speaking background (Taylor and Toohey, 1998).

Previous research would suggest that the construction of sports discourses and its organisational antecedents have been problem- 
atic for many marginal groups within society. Explicit barriers such as language differences, inadequate information, program/sports selection, and less direct barriers such as different cultural expectations and assumptions, discriminatory attitudes practices and assimilation-based thinking all contribute to less than ideal access and equity in sports. Exclusionary attitudes structured on gender lines are not just found within mainstream sporting communities. For example Mosely (1997) reported in his case study of bocce in Australia that Italian males successfully excluded women from the sport until the late 1960s when they were admitted into clubs. However, sustained male opposition led to a subsequent decline in the number of female bocce participants. Similarly, an historical study of Greek-Australians, Georgakis (1999) found that while Greek males have used sports activity to maintain their cultural identity in their new country, Greek women were systematically excluded from forming sports team within Greek community clubs until the 1960s. Hughson's (1996) research with soccer supporters of a Croatian club team revealed that the supporters' activities acted to exclude women and promote a masculine identity that was highly misogynistic. The extent to which community sport clubs are inclusive of female cultural diversity is a prime consideration in the research undertaken for this paper.

\section{Research Aim and Method}

The purpose of the study was to create a profile of gender and cultural diversity in community sport organisations in order to further our knowledge and understanding of diversity issues in sport. The profile covered three distinct aspects within community sports organisations:

1. Audit of gender and cultural diversity strategies, policies and practices

2. Diversity analysis of athletes, general volunteers and officials (coaches, umpires, etc.)

3. Assessment of the level of understanding and acceptance of cultural diversity.

These aims were developed to address the need for more in-depth organisational analyses to develop and support meaningful sport policies and practices (Allison, 1999; Doherty \& Chelladurai, 1999).

The study focused on five team sports and their community club operations. The sports chosen ranged from sports traditionally associated with cultural similarity to those associated with cultural difference. Each sport had a significant female participation base. The five sports were: bocce, hockey, netball, softball and volleyball. A survey was conducted to collect baseline club data on each of the three profiling components. Questions were a primarily closed ended with opportunity provided for further comments and focussed on the club's policies and practices for managing gender and cultural diversity. Issues canvassed related to the club's policies, principles, and practices that underpin diversity issues, the details of those efforts and any associated problems or obstacles, and the perceived value of increasing gender and cultural diversity.

The questionnaires were distributed to community sport club presidents of the five sports in ten regions across New South Wales. The regions were systemically selected to represent state-wide coverage, city and country

Table 1: Response rate to Questionnaire Survey

\begin{tabular}{lccc}
\hline Sport & $\begin{array}{c}\text { Number of } \\
\text { questionnaires returned } \\
\text { (out of 10) }\end{array}$ & $\begin{array}{c}\text { Number of club } \\
\text { representatives } \\
\text { interviewed }\end{array}$ & $\begin{array}{c}\text { Number of members in } \\
\text { focus group }\end{array}$ \\
\hline Bocce & 8 & 2 & 7 \\
Hockey & 9 & 2 & 6 \\
Netball & 9 & 2 & 8 \\
Softball & 8 & 2 & 8 \\
Volleyball & 7 & 2 & 37 \\
Total & 41 & 10 & 87 \\
\hline
\end{tabular}


clubs and clubs from geographical areas with both high and low levels of minority ethnic populations. A single mailout of the self-completed questionnaire was distributed with fax or mail (reply-paid) return options. As outlined in Table 1, an 82 per cent response rate was achieved.

Follow up interviews were conducted with two club representatives from each selected sport. The club with the highest and lowest reported levels of gender and cultural diversity inclusiveness were selected for the interview phase. Each of these clubs agreed to publicise a request for female players from diverse cultural backgrounds to volunteer for focus group discussions. Between two and four female players volunteered for each group and they were asked about their perceptions of the club's response to diversity matters ranging from policy issues to cultural inclusiveness. All sessions were facilitated by the researcher and audio taped for transcription and analysis. A total of 37 women took part in the focus group discussions, which lasted from 45 to 180 minutes.

\section{Findings}

In this section the results of the questionnaire survey are presented in tandem with the interview and focus group discussions. The issues coalesced around three issues, the club's gender and cultural diversity strategies, policies and practices; the level of understanding and acceptance of diversity; and attitudes to increasing the diversity of their club membership. Each club was asked to rank their present level of policy development and practices in gender and cultural diversity management. A series of questions were then used to ascertain how the club viewed their current position on diversity. Respondents were asked to list any problems or obstacles that they felt existed to increasing gender and cultural diversity within the club, and if the club could benefit from increasing their levels of diversity. The responses to these questions were then used to locate the club on a continuum of gender and cultural inclusiveness.

\section{Respondent Characteristics}

The club respondents were primarily middle aged ( $49 \%$ at $30-49$ years), followed by those aged over 50 years $(40 \%)$ and complemented by a smaller proportion of younger presidents $20-29$ years ( $11 \%)$. Some 76 percent of the respondents had competed in sport at the club level, 16 percent at the national level and 8 percent at international levels. Many were still active as players (56\%), coaches $(62 \%)$ or game officials ( $25 \%)$. Most club presidents (68\%) were born in Australia, 17 per cent were born in other English-speaking countries and $17 \%$ in non-English-speaking countries. Of the latter group all but one came from the sport of bocce (see Table 2).

\section{Club Profiles}

Table 3 provides the respondents' estimates of the gender and cultural diversity of club members. As the data indicate, there are considerable variations between sport clubs on both dimensions. For example in bocce the proportion of Australian born club members is relatively low, which in itself is not surprising given that in Australia bocce was historically developed by Italian social club. Some 85 per cent of the clubs indicated that they had spe-

Table 2: Gender and cultural background of club presidents

\begin{tabular}{lccccc}
\hline Sport & No. of females & No. of males & $\begin{array}{c}\text { Nos. born in } \\
\text { Australia }\end{array}$ & $\begin{array}{c}\text { Nos. born in an } \\
\text { English speaking } \\
\text { country }\end{array}$ & $\begin{array}{c}\text { Nos. born in an } \\
\text { non- English } \\
\text { speaking country }\end{array}$ \\
\hline Bocce & 1 & 7 & 1 & 1 & 6 \\
Hockey & 3 & 6 & 7 & 2 & 0 \\
Netball & 9 & 0 & 8 & 1 & 0 \\
Softball & 6 & 2 & 7 & 2 & 0 \\
Volleyball & 1 & 6 & 5 & 1 & 1 \\
Total & 20 & 21 & 28 & 7 & 7 \\
\hline
\end{tabular}


Table 3: Gender and cultural background of club members

\begin{tabular}{lcccccc}
\hline Sport & Estimated \% of players & \multicolumn{2}{c}{ Estimated \% of volunteers } & \multicolumn{2}{c}{ Estimated \% of officials } \\
\hline Female & $\begin{array}{c}\text { Australian } \\
\text { born }\end{array}$ & Female & $\begin{array}{c}\text { Australian } \\
\text { born }\end{array}$ & $\begin{array}{c}\text { Female } \\
\text { born }\end{array}$ \\
\hline Bocce & 40 & 20 & 45 & 10 & 15 & 05 \\
Hockey & 75 & 90 & 80 & 90 & 65 & 95 \\
Netball & 90 & 90 & 98 & 95 & 95 & 95 \\
Softball & 80 & 85 & 85 & 90 & 75 & 90 \\
Volleyball & 40 & 75 & 55 & 70 & 25 & 70 \\
\hline
\end{tabular}

cific policies or strategies on gender equity. However, only 16 per cent of the clubs surveyed indicated that they had explicit policies on cultural diversity. Given this response it is not surprising that while all $(100 \%)$ of the clubs indicated that they felt it was highly important to encourage female involvement in their clubs, few clubs felt the same about increasing ethnic diversity. These estimated levels of cultural diversity within sport clubs was then compared to the level of cultural diversity in their constituent region. Using 1996 census data it was calculated that people born outside of Australia were significantly less likely to be club members than their Australian-born counterparts. The finding suggests that clubs are significantly lower than the leviel of cultural diversity present in their catchment region.

The one exception to this was bocce, which was significantly above the regional level for cultural diversity. As one of the bocce club representatives explained, 'we have a really strong base in the Italian community but need to expand it because of the aging nature of those migrants. We need new blood and we are trying to get other groups into the club.' At the other end of the continuum were the hockey and netball clubs who reported few members from other countries. A hockey club representative explained that her club did not appear to attract many of the local Lebanese or Vietnamese population, 'in particular the girls just don't seem to have the same level of interest. I think that their parents feel hockey is too rough and not a game for their respectable daughters.'

According to the club responses women tended to be over-represented as volunteers and under-represented as officials, while nonAustralian born members were less likely to be volunteers or officials than players. One of the netball players interviewed said that while many of her friend's mothers did volunteer work for the club her mother did not volunteer because she grew up in Yugoslavia, 'she has no idea about netball and her English is not strong so she feels too embarrassed to come out and do something.' A softball player said that she felt the mothers did all the non-technical volunteer jobs while, 'the dads seem to mainly be coaches and umpires, that is if they help out at all.'

\section{Attitudes to diversity}

The data in Table 4 suggest that sports clubs feel that they are encouraging female involvement for player, official and volunteer roles. These responses were strongest in the female dominated sports of netball and softball. Most of the sports surveyed reported that they were already doing enough to promote gender equity. These sentiments were subsequently reinforced in the interviews. The interviewees from netball and softball clubs said that their sports were very supportive of women. A netball player/coach who was born in Samoa offered this viewpoint, 'netball is game for us and it's all the women who make the club possible, who run things and have been doing so for years and years. Every girl is made welcome to play never mind her size or speed.' The women involved in volleyball and bocce that were interviewed were not as equivalently positive. As Gina, an Italian-born mother of four said, 'my husband plays bocce too and he seems to get the better deal in this 
Table 4: Issues of gender and cultural diversity

\begin{tabular}{|c|c|c|c|c|}
\hline \multirow[b]{2}{*}{ Mean responses to: } & \multicolumn{2}{|c|}{$\begin{array}{l}\text { The club currently endeavours to } \\
\text { foster greater involvement of: }\end{array}$} & \multicolumn{2}{|c|}{$\begin{array}{l}\text { The club should be doing more } \\
\text { to foster greater involvement of: }\end{array}$} \\
\hline & Women & $\begin{array}{c}\text { People from } \\
\text { diverse } \\
\text { cultures }\end{array}$ & Women & $\begin{array}{c}\text { People from } \\
\text { diverse } \\
\text { cultures }\end{array}$ \\
\hline As players & 2.07 & 5.18 & 3.74 & 3.07 \\
\hline As coaches/officials & 3.29 & 5.84 & 3.98 & 3.14 \\
\hline In other volunteer roles & 3.12 & 5.07 & 3.84 & 3.16 \\
\hline As members of committees & 3.10 & 6.11 & 3.53 & 3.98 \\
\hline In paid positions & 4.33 & 6.11 & 3.33 & 4.16 \\
\hline
\end{tabular}

place. We (women) have to make the best with what is left over.' Anna, a Dutch-born volleyball player expressed similar sentiments, 'the top men's team in this club gets the best coach, the best practice time, the new balls. We (the top women's team) do alright but it is never quite equal.'

Few clubs reported a strong commitment to fostering greater cultural diversity, and did they not perceive it as an area in which they should be doing more. The one exception was bocce. Traditionally not a major Australian sport, bocce club respondents expressed a strong desire to attract more participants from Anglo-Australian backgrounds and to expand their ethnic base. Maria explained. 'we (bocce) are trying now to get the game into more schools, we need young players. My son plays but trying to get other youngsters to play is difficult when you are competing with the Aussie sports on TV.'

Most of the focus group participants did not feel that increasing cultural diversity was a pressing issue. However, these are the very people who are already club members. As one of the hockey club players reflected, 'I don't see it as a big deal but then I played hockey in school with my friends... if you just came here and couldn't speak English it might be more difficult as everything is done in English and most of us in the club grew up together.' Similarly, Wendi learned" to play netball in Hong Kong and found the transition into the Australian club system easy. 'Well, I didn't need any special help just because I was born in another country but let me tell you there are not too many Asian girls that play and you have to ask why since there are certainly a lot living around this area.' Table 5 outlines the level of commitment the club's have across several dimensions of diversity practices.

The focus group participants were asked for comments on their experiences of any of the five identified diversity practices. All of the focus group participants agreed that that sports clubs were much better at encouraging diversity now than in the past. However, the extent to which clubs could be doing more on

Table 5: Diversity Practices

\begin{tabular}{lcccc}
\hline My club encourages ... & \multicolumn{2}{c}{ For Women } & \multicolumn{2}{c}{ For Cultural diversity } \\
\hline & Mean & Std. Dev. & Mean & Std. Dev. \\
\hline Equity and access of opportunities & 2.47 & 1.08 & 3.13 & 1.01 \\
Provision of safe environments & 3.37 & 1.11 & 4.07 & 1.07 \\
Sexual/Cultural respect & 3.72 & 1.14 & 4.25 & 1.12 \\
Role models & 3.74 & 1.13 & 3.98 & 1.14 \\
Segregated programs & 1.88 & 1.08 & 3.41 & 1.05 \\
\hline
\end{tabular}

$1=$ totally agree and $7=$ totally disagree 
these dimensions elicited varying responses. It was pointed out by the Asian women interviewed that there are very few female Asian role models in most sports. One participant said that while women hockey players were respected as sportswomen she felt that her club deliberately steered clear of sexual diversity issues. Another believed that the special female-only coaching clinics that she was running for her volleyball club provided girls with access to programs where they could learn to play away from the ridicule of boys. She felt that this was particularly important for girls from strongly patriarchal cultural backgrounds.

The survey respondents did not indicate any significant problems or obstacles in encouraging gender diversity. However, in reply to the same question for cultural diversity the respondents highlighted a number of issues. In response to the question 'are there specific cultural groups in your community that do not use your club?" Eight-seven per cent of the respondents indicated 'yes'. Asked why these groups were not joining the club the responses were, 'not interested' (88\%) 'poor English language' (52\%) and 'cultural limitations' (46\%). One of the hockey club representatives interviewed said, 'we have large numbers of Asian girls living around here But they don't play probably because they aren't encouraged by their parents who want them to study and the like.' A volleyball representative expressed the view that, 'we get players from places where the game is popular like Europe and South America but the others don't seem to be interested. As for women, some cultures like the Muslims, Lebanese and such don't like their women to play.'

Nearly 85 per cent of the survey respondents felt that their club could 'not afford' to specifically target ethnic groups. As one respondent wrote, 'we just couldn't afford to print our material in other languages or get or pay translators.' Nearly 90 per cent indicated that they believed the club's existing policies and operations did not discourage cultural diversity. A majority of the survey respondents (78\%) replied that targeting specific cultural groups would be inappropriate and 60 per cent believed that such initiatives would disaffect existing club members. 'I would hate our club do go down that track (encouraging cultural diversity) we wouldn't want to get into the same ethnic dilemma that soccer found itself faced with, you know spectator violence and ethnic tensions' (hockey club representative). The benefits associated with increasing diversity were seen to be increased participation, the value of different perspectives and a more representative community involvement.

\section{Discussion}

The clubs with the largest membership bases, in numerical terms, were the most intractable on the need to increase cultural diversity. In particular, these clubs perceived the manifestation of cultural diversity as a prerogative of government and social organisations and not the responsibility of community clubs. Undeterred by the shifts in government policy in the 1970s and 1980s from assimilation to cultural diversity, many of the clubs operate on the basis of one unified Australian culture and do not see the necessity of more proactive approaches to bring them into the twenty-first century. So pervasive is this acceptance of cultural dominance that it is ingrained in organisational practices. For the majority of clubs an open-door policy has sufficed as their primary cultural diversity initiative. In this way cultural diversity is dissimilar to the gender issue, which has been the subject of initiated change and heightened awareness about inequities. Cultural diversity dimensions are rarely highlighted and are instead blended into an amorphous sporting milieu.

While most of the focus group participants believed that clubs had become more diverse over the last few decades there was little evidence to suggest that contemporary sports clubs particularly valued cultural diversity within their organisations. Many of the club respondents did not feel that there was any need to instigate a change in policy or practice to promote the involvement of people from other cultural backgrounds. This ethnocentric perspective is reflective of the complexities of Australian social relations and policy found in other research on ethnicity (Bottomley, de 
Lepervanche and Martin, 1991). Encapsulated in the establishment and organisation of sports clubs in this country is over 100 years of white history concentrated in the hands of the dominant cultural group. While sports clubs have evolved from outright exclusion of certain ethnic and racial groups to subsequently assimilate other cultural groups into their mainstream operations, few sports have actually taken the next step of valuing cultural diversity in their organisations.

Organisational reluctance to embrace cultural diversity may be in part explained by club's concerns about retaining the current mainstream participant base if cultural diversity is simultaneously targeted. Such conflicts have been noted in organisational studies literature (Mendoza, 1999). The evidence suggests that inaction on issues of cultural diversity may be based on one or more of five commonly held assumptions. Firstly, sports clubs seem to believe that directing resources into the recruitment of players from culturally diverse backgrounds would conversely mean taking resources away from the core player base and therefore not be equitable. Secondly, is the assumption that any added resources, polices and efforts would not translate into sufficient player numbers to justify the expenditure. Third, is the belief that the recruitment of players from specific ethnic backgrounds would have the potential to alienate mainstream support. Fourthly, it is assumed that many people from particular cultural and religious backgrounds are 'not interested' or do not want to join their club for immovable cultural reasons. And finally, is the conviction that eventually all interested parties will culturally assimilate into the mainstream offerings.

Why change? The first argument is founded on moral and equity considerations. The development of inclusive policies and practices within sport organisations, together with more inclusive sport discourses, will ultimately translate into fewer cultural and gender constraints to sports participation. The right of an individual to choose to participate in sports and the attendant quality of life issues are central to this argument. Sports participation can provide people with the oppor- tunity to be part of their communities and develop social relationships. The present reality of inadequate gender and cultural inclusion and the historical rationales for perpetuating assimilation practices in sports needs to be transformed. This requires an ideological shift and accompanying attitude change. Unless such change can be fully justified it is unlikely to happen. So addition to the moral and equity arguments I suggest that there are practical and even financial reasons for changing sports practice.

Secondly, future government funding is to be linked to the ability of sports to increase physical activity levels and demonstrate that they are providing for all sectors of the population (Commonwealth of Australia, 2000). In effect, sport organisations will need to demonstrate that they are inclusive of women and cultural diversity for future funding. In addition the new funding schemes stress increased selffunding. By expanding their participant base sports organisations will increase their potential to attract sponsorship and donor monies from non-government sources.

The third argument relates to 'pure and simple' survival into the new millennium and good business acumen. The increased choice of a wide array of sports has meant a dispersion of traditional player, volunteer and spectator bases. As the competition for patrons intensifies the ability of sports to target, attract and retain females and males from diverse cultural backgrounds will be of increasing importance. The provision of a culturally supportive sports environment would give the sport an advantage in this regard.

Fourthly, it has been previously demonstrated that individual sports clubs such as Canterbury and Carlton have successfully pursued talent from outside the mainstream. The player base of these clubs has expanded and a number of elite level players have emerged from this process. Additionally, community support has increased across several dimensions from school sport to spectators and ethnic business sponsorships.

Finally, the contention that gender and ethnic inclusion will be necessarily a substantial expense is not tenable. What is required is an 
attitudinal shift, a change in the way sports are spoken about and conceptualised. To foster a better understanding and awareness about the needs and requirements of women and cultural diversity is not expensive. The implementation of polices to encourage participation across all cultural groups might incur some initial additional costs but these issues would soon evolve into current practice. For example, using an image of a Muslim woman playing softball in a marketing campaign would be the same cost as using the image of an Anglo-Australian male.

Understanding, respecting and acknowledging the tenets of cultural diversity are essential considerations in developing an inclusive sports environment (Australian Sports Commission, 2000). Theoretically, creating a better understanding of all cultures and environments would facilitate a situation where the contribution of members of cultural groups was valued positively (Elmes \& Connelley, 1997). 'How we perceive other people affects how we behave towards them and how they, in turn behave towards us' (Robinson, 1988 p49). The development of a hybrid sporting culture that breaks down constraints to participation and promotes inclusivity is an opportunity to challenge existing ethnocenitric and patriarchal systems that have been proven to be exclusionary and deterministic. Australian sport has the potential to create a symbolic space in which ethnic and cultural difference can be accepted and valued.

As identified by previous researchers (Fleming, 1994; Long et al., 1997; Taylor, 2000) many of the informal and exclusionary rules of entry into sports are so entrenched that those who have been socialised into sport fail to recognise how their practices, policies and procedures continue to promote inequity, insensitivity and/or access. Not surprisingly, the present research clearly revealed that internalised institutional responses both implicitly and explicitly maintain the inherent inequities of opportunity and have been highly resistant to attempts to ameliorate inequity. A combination of social and cultural forces has led to the present sport participation patterns of women from culturally diverse backgrounds.

\section{Conclusions}

Unless gender and cultural inclusivity is actively pursued it is unlikely to simply 'happen'. To date the adoption of generic approaches to the provision of sports services and programs for diversity have not offered inclusive solutions. The practice of ignoring difference and providing generically constructed services has neglected specific needs and perpetuated structural discrimination. Cultural practices that are not in accord with the traditions of the dominant Anglo-Australian way of life have been resisted and cultural diversity only tolerated when the cultural difference has been ideologically acceptable to the mainstream powerbrokers. On the other hand, basing service delivery on ethnicity dimensions has the potential to segregate and marginalise mainstream participants. In attempts to avoid the inevitable conflict that arises from divergent cultures trying to co-exist sport provision has focussed on retaining sameness rather than re-negotiating these sporting spaces.

Sport organisations need to better address diversity priorities. These include building a commitment to the change process in organisational practice and discourse through the development of an organisational awareness of diversity issues and how these impact sports organisation and delivery; membership acknowledgment of cultural considerations including customs, values, and mores; introduction of strategies that will remove gender and cultural barriers to participation; challenging organisational and community stereotypes that may limit participation; provision of access to cultural diversity training and development for staff and volunteers of sports organisations; adopting recruitment and selection practices for new staff and volunteers which are culturally inclusive; identification of language and communication barriers in program design, promotion, delivery and evaluation; and the development of mentoring schemes for players, coaches, referees, administrators and volunteers. Sports should strive to provide the 'level playing field' where all Australians cheer each other on to reach their full potential. 
The changing nature of sport combined with a shifting demographic will create challenges for many sport organisations in the future. The country's population will be reshaped with respect to age and ethnic composition. The expected diversity of the population will require organisations to recognise the unique needs and cultural backgrounds of their future sports participants, volunteers, spectators and employees. In short, sport organisations will be forced to take a different approach, one that values gender and cultural diversity in the context of the organisation's needs, circumstances, and philosophy. Organisations, which can effectively manage this diversity, will have a significant competitive edge in such a sports environment.

\section{REFERENCES}

Adair, D. (1998). Conformity, diversity, and difference in Antipodean physical culture: The indelible influence of immigration, ethnicity, and race during the formative year of organised sport in Australia, c.1788-1918. Immigrants and Minorities, 17 (1), 14-44.

Allison, M.T. (1999). Organizational barriers to diversity in the workplace. Journal of Leisure Research 31(1), 78-101.

Armstrong, T., Bauman, A., \& Davies, J. (2000). Physical activity patterns of Australian adults. Results of the 1999 National Physical Activity Survey. Canberra: Australian Institute of Health and Welfare.

Australian Bureau of Statistics. (1998). Involvement in sport, Australia 1997-1998. Canberra: Australian Bureau of Statistics.

Australian Bureau of Statistics (2000). Australia in Profile. Canberra: Australian Bureau of Statistics.

Australian Sports Commission (2000). The numbers game: A description of organised sport and physical activity participants in Australia. Canberra: Australian Sports Commission.

Bhabha, H. (1990). Introduction: Narrating the nation. In H. Bhabha (Ed.). Nation and Narration. (pp. 1-7), London: Routledge.

Bhandari, R. (1991). Asian action. Sport and Leisure, $32(5), 24-25$.

Booth, D., \& Tatz, C. (2000). One-eyed: A view of Australian sport. St Leonards: Allen and Unwin.

Bottomley, G., de Lepervance M., \& Martin, j. (Eds.). (1991). Intersexions gender/class/culture/ethnicity. Sydney: Allen \& Unwin.

Cashman, R. (1995). Paradise of sport: The rise of organised sport in Australia. Melbourne: Oxford University Press.
Clarke, G., Humberstone, B., \& Hargreaves, J. (1997). Researching women and sport. Basingstoke: Macmillan.

Clegg, S., \& Hardy, C. (Eds.). (1999). Studying organization: Theory and method. London: Sage.

Commonwealth of Australia.(1999.) Shaping up: A review of Commonwealth involvement in sport and recreation in Australia. Canberra: AGPS.

Connell, R.W. (1990). An iron man: The body and some contradictions of hegemonic masculinity. $\ln M$. Messner and D. Sabo (Eds.), Sport, men and the gender order: Critical feminist perspectives. Champaign, III.: Human Kinetics Press.

Cox, T. (1994). Cultural Diversity in organisations: theory, research and practice. San Francisco: BerrettKoehler.

Dagher, J. \& D'netto, D. (1997). Managing workforce diversity in Australia. Caulfield East, Vic : Dept. of Management, Monash University.

Department of Immigration and Multicultural Affairs (1999) Population Flows: Immigration Aspects January 1999 Canberra: DIMA.

Doherty, A.J. \& Chelladurai, P. (1999). Managing cultural diversity in sport organizations: a theoretical perspective. Journal of Sport Management 13(4), pp.280-297.

Duchatelet, $M$. (1998) Cultural diversity and management/leadership models. American Business Review. 16(2): 96-99.

Elmes, M., \& Connelley, D. (1997) Dreams of diversity and the realities of intergroup relations in organisations. In P. Prasad, A. Mills, M. Elmes \& A. Prasad (Eds.), Managing the organisation melting pot: Dilemmas of workplace diversity (pp. 148-167). Thousand Oaks: Sage Publications.

Fitzpatrick, M. \& Brimage, G. (1998). Careers in sport and recreation in Western Australia. Perth: Ministry of Sport and Recreation.

Fleming, S. (1994). Home and away: Sport and South Asian male youth. Aldershot: Avebury.

Georgakis, S. (1999). Greek sporting traditions in Australia: An historical study of ethnicity, gender and youth. PhD thesis unpublished, University of Sydney.

Gomez-Mejia, L. \& Palich, L. (1997). Cultural diversity and the performance of multinational firms. Journal of International Business Studies. 28 (2): 309-336.

Hall, M.A. (1996). Feminism and sporting bodies: Essays on theory and practice. Campaign: Human Kinetics.

Hargreaves, J. (1993). Gender on the sports agenda. In A. Ingham and J. Loy (Eds.), Sport in social development: Traditions, transitions and transformations. (pp. 167-185). Champaign: Human Kinetics.

Hargreaves, J. (1994). Sporting Females: Critical issues in the history and sociology of women's sports. London: Routledge.

Hay, C. (1996). Managing cultural diversity: opportunities for enhancing the competitive advantage 
of Australian business. Canberra: Australian Govt. Pub. Service.

Henderson, K., \& Ainsworth, B. (2000) Enablers and constraints to walking for older African American and American Indian Women: The cultural activity participation study. Research Quarterly for Exercise and Sport. 71 (4), 313.

Henderson, K.A., \& Bialeschki, D.M. (1994). Women and the meanings of physical recreation. Women in Sport and Physical Activity Journal, 3 (2), 21-37.

Herriot, P. (1995). Competitive advantage through diversity: organizational learning from difference. London; Thousand Oaks: Sage Publications.

Hooks, B. (1989). Feminist theory: From margin to center. Boston: South End Press.

Hughson, J. (2000). The boys are back in town: Soccer support and the social reproduction of masculinity. Journal of Sport \& Social Issues, 24 (1) , 8-23.

Jarvie, G. (1991). There ain't no problem here? Sport \& Leisure, 20-21.

Kalantzis, M. (1992). Managing cultural diversity. Haymarket: NLLIA Centre for Workplace communication and Culture.

Long, J., Carrington, B., \& Spracklen, K. (1997). "Asians cannot wear turbans in the scrum": explorations of racist discourse within professional Rugby League. Leisure Studies, 16 (4) , 249-259.

Mendonsa, R. M (1999) Riding the Waves of Culture: Understanding Cultural Diversity in Business. Human Resource Development Quarterly. 10(2):185188.

Milliken, F. J. \& Martins, L. (1996).. Searching for common threads: Understanding the multiple effects of diversity in organizational grobups. Academy of Management Review. 21 (2): 402-433.

Mohapatra, M. K. (1996). Administrators' Attitudes toward Cultural Diversity Management: An Empirical Study. Indiana State Univ., Terre Haute: Center for Governmental Services.

Mosely, P. (1994). Life and sweaty: Ethnic communities at play. In D. Headon, J. Hooton \& D. Horne (Eds.). The abundant culture: Meaning and significance in everyday Australia (pp. 198-204). St Leonards: Allen \& Unwin.

Mosely, P. (1997). Australian sport and ethnicity. In P. Mosely, R. Cashman, J. O'Hara, \& H. Weatherburn (Eds.), Sporting immigrants (pp. 13-42). Crows Nest: Walla Walla Press.

Mosely, P., Cashman, R., O'Hara, J., \& Weatherburn, H. (Eds.) (1997). Sporting immigrants. Crows Nest: Walla Walla Press.

$\mathrm{Ng}$, E. \& Tung, R. (1998) Ethno-cultural diversity and organizational effectiveness: a field study. International Journal Human Resource Management. 9 (6): 980 - 0995.

Palich, L.E. Gomez-Mejia \& L.R (1999). A theory of global strategy and firm efficiencies: Considering the effects of cultural diversity. Journal of Management. 25(4): 587-606.

Paraschak, V. (1996) Book Reviews. Journal of Sport History, 23 (2), 187-191.

Prakash, G. (1994). Postcolonial criticism and Indian historiography. In L. Nicholson \& S. Seidman (Eds.), Social postmodernism: Beyond identity politics (pp. 87-100). Cambridge: Cambridge University Press.

Robinson, G. (1988). Cross-cultural understanding. London: Prentice-Hall.

Roosevelt. T. (1991). Beyond race and gender: unleashing the power of your total work force by managing diversity. New York: AMACOM, American Management Association.

Rowe, D. (1996). Popular Cultures: rock music, sport and the politics of pleasure. London: Sage Publications.

Stoddart, B. (1994). Reflections past and present. In W. Vamplew \& B. Stoddart (Eds.), Sport in Australia: A social history (pp. 269-283). Melbourne: Cambridge University Press.

Strydom, J. B., \& Erwee, R. (1998). Diversity management in a sample. of South African companies. South African Journal of Business Management, 29 (1), p14-21.

Taylor, T. (2000) Women, sport and ethnicity in sports leadership. International Review of Women and Leadership, 6 (1): 1-15.

Taylor, T. \& Toohey, K.(1999) Sport, Gender and Cultural Diversity: Exploring the Nexus. Journal of Sport Management, 13 (1) 1-17.

Taylor, T., \& Toohey, K. (1998) Negotiating cultural diversity for women in sport: from assimilation to multiculturalism. Race, Ethnicity and Education, 1(1) 75-91.

Toohey, K. \& Taylor, T. (1997) Sport provision for women of minority cultures in Australia. Women in Sport \& Physical Activity Journal 6(2) 254-264.

Theberge, N., \& Birrell, S. (1994a). The sociological study of women and sport. In D.M. Costa \& S. Gutherie (Eds.), Women and sport: Interdisciplinary perspectives (pp. 323-330). Champaign: Human Kinetics.

Theberge, N., \& Birrell, S. (1994b) Structural constraints facing women and sport. In D.M. Costa \& S. Gutherie (Eds.), Women and sport: Interdisciplinary perspectives (pp. 331-340). Champaign: Human Kinetics.

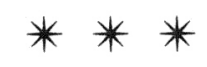

TRACY TAYLOR, PhD
Deputy Head, School of Leisure, Sport \& Tourism
University of Technology, Sydney
PO Box 222, Lindfield NSW 2070
E-mail: Tracy.Taylor@uts.edu.au 